\title{
Improvement of structural and superconducting properties of Bi-2212 textured rods by
} substituting sodium

\author{
O. Nane ${ }^{* a}$, B. Özçelik ${ }^{b}$, A. Sotelo ${ }^{c}$, M. A. Madre ${ }^{c}$ \\ ${ }^{a}$ Department of Material Science and Engineering, Faculty of Engineering, Hakkari \\ University, 30000 Hakkari, Turkey \\ ${ }^{\mathrm{b}}$ Department of Physics, Faculty of Sciences and Letters, Çukurova University. 01330 Adana, \\ Turkey \\ ${ }^{\mathrm{c}}$ ICMA (CSIC-Universidad de Zaragoza). María de Luna, 3. 50018 Zaragoza, Spain.
}

\begin{abstract}
In this study, the physical and superconducting properties of $\mathrm{Bi}_{2} \mathrm{Sr}_{2} \mathrm{Ca}_{1-\mathrm{x}} \mathrm{Na}_{\mathrm{x}} \mathrm{Cu}_{2} \mathrm{O}_{8+\delta}(\mathrm{x}=0.0$, $0.05,0.0750 .1$, and 0.20 ) textured superconducting rods prepared by a laser floating zone technique were presented. The effect of $\mathrm{Na}^{+1}$ substitution for $\mathrm{Ca}^{2+}$ has been investigated by $\mathrm{X}$ ray diffraction, scanning electron microscopy, energy dispersive X-ray spectroscopy, transport measurements, dc-magnetization, magnetic hysteresis and magnetic critical current density. The powder XRD patterns of samples have shown that Bi-2212 phase is the major one, independently of $\mathrm{Na}$ content. Transport measurements indicate that, in general, the transport critical current density of samples is increased by Na substitution compared with the pure sample. In all cases, a good orientation of grains with the growth axis was observed in microstructural studies. The best critical temperature, $T_{C}$, was found as $93.3 \mathrm{~K}$ for the sample with $0.75 \mathrm{Na}$ substitution, under a DC magnetic field of 50 Oe in ZFC mode. It was also observed that the magnetic critical current density obtained from magnetic hysteresis curves by using the critical Bean's model, increases with increasing Na-substitution. The maximum magnetic $J_{C}$ value was determined as $1.35 \times 10^{5} \mathrm{~A} / \mathrm{cm}^{2}$ at $10 \mathrm{~K}$ for the $0.10 \mathrm{Na}$ sample. The maximum transport critical current density was directly measured as $1.3 \times 10^{3} \mathrm{~A} / \mathrm{cm}^{2}$ at $77 \mathrm{~K}$ for the $0.05 \mathrm{Na}$ sample.
\end{abstract}

\section{Keywords}

Bi-2212, Sodium Substitution, Magnetic Properties, Critical Current Density $\mathrm{J}_{\mathrm{C}}$, Texturing, Laser Floating Zone Technique. 


\section{Introduction}

The BSCCO family can be described by the $\mathrm{Bi}_{2} \mathrm{Sr}_{2} \mathrm{Ca}_{n-1} \mathrm{Cu}_{n} \mathrm{O}_{2 n+4+y}$ general formula, where $\mathrm{n}=1,2$, and 3 . The $\mathrm{n}$ value indicates the number of $\mathrm{CuO}_{2}$ layers in the crystal structure, producing the Bi-2201, Bi-2212 and Bi-2223 phases with critical temperatures, $T_{c}$ 's, of about 20,85 , and $110 \mathrm{~K}$, respectively [1,2]. Among these phases, the $\mathrm{Bi}-2212$ is stable in a wide range of compositions and processing temperatures but its $T c$ is greatly influenced by the chemical composition. Tc increases significantly when the $\mathrm{Bi}$ and $\mathrm{Ca}$ content is decreased, provided that the oxygen content is constant [3]. Since their discovery many experiments have been performed to better understand their structural and physical properties of the system, and to improve their critical temperature $(T c)$ and critical current density $\left(J_{c}\right)$ [4-17], as it is considered as one of the most promising materials for technological applications. Besides, BSCCO superconductors have some advantages as high critical temperature and magnetic field carrying capacity, they also have some disadvantages like the weak-links, high anisotropy, and small coherence length. These restrict them for technological applications. Generally, even very small misorientation of grains in BSCCO superconductors produces a negative effect on $J_{c}$ values. For many years, researchers have used many strategies in order to overcome those disadvantages and to maximize the transport properties at $77 \mathrm{~K}$.

When BSCCO materials are properly textured, their transport properties are improved, in an important manner, compared with the non-textured materials. The Laser Floating Zone (LFZ) technique has been demonstrated to be an effective technique to produce a good grain orientation in Bi-2212 superconductors [18-22]. This method produces very high thermal gradients in the solidification front, producing a preferential alignment of grains with their caxis perpendicular to the growth direction [23], maximizing the transport properties in the direction parallel to the growth axis.

In our previous works, the effect of sintering temperature on the Bi-(2212) phase formation, the optimum $\mathrm{Na}$ content to obtain the maximum amount of Bi-2212 phase and on the intergranular properties of polycrystalline $\mathrm{Bi}_{2} \mathrm{Sr}_{2} \mathrm{Ca}_{1-\mathrm{x}} \mathrm{Na}_{\mathrm{x}} \mathrm{Cu}_{2} \mathrm{O}_{8+\mathrm{y}}$ samples prepared by polymer method were studied [15,16,24]. Therefore, in this study, we have investigated the effects of $\mathrm{Na}^{+1}$ substitution for $\mathrm{Ca}^{+2}$ in Bi-2212 textured ceramics prepared by using the LFZ technique. X-ray diffraction, scanning electron microscopy, energy dispersive X-ray spectroscopy, transport measurements, dc-magnetization, magnetic hysteresis and magnetic critical current density were used to characterize the prepared samples. 


\section{Experimental}

The initial $\mathrm{Bi}_{2} \mathrm{Sr}_{2} \mathrm{Ca}_{1-\mathrm{x}} \mathrm{Na}_{\mathrm{x}} \mathrm{Cu}_{2} \mathrm{O}_{\mathrm{x}}$ polycrystalline materials used in this work were prepared by a polymer solution method [25]. $\mathrm{Bi}\left(\mathrm{CH}_{3} \mathrm{COO}\right)_{3}\left(\geq 99.99 \%\right.$, Aldrich), $\mathrm{Sr}\left(\mathrm{CH}_{3} \mathrm{COO}\right)_{2} \bullet 0.5 \mathrm{H}_{2} \mathrm{O}$ (99 \%, Panreac), $\mathrm{Ca}\left(\mathrm{CH}_{3} \mathrm{COO}\right)_{2} \cdot 2 \mathrm{H}_{2} \mathrm{O}\left(98 \%\right.$, Alfa Aesar), $\mathrm{Na}\left(\mathrm{CH}_{3} \mathrm{COO}\right) \cdot 3 \mathrm{H}_{2} \mathrm{O}(\geq 99.99$ $\%$, Aldrich), and $\mathrm{Cu}\left(\mathrm{CH}_{3} \mathrm{COO}\right)_{2} \cdot \mathrm{H}_{2} \mathrm{O}(98 \%$, Panreac) commercial powders were used as starting materials. They were weighed in the appropriate proportions and dissolved in a mixture of distilled $\mathrm{H}_{2} \mathrm{O}$ and glacial acetic acid (ACS Reagent, Panreac). Once a light clear blue solution has been obtained, polyethyleneimine (PEI, 50\% aqueous, Aldrich) was added, turning it darker immediately due to the formation of metal cation-PEI complexes [26]. The solution was then introduced in a rotary evaporator where the volume was reduced to about 20 $\%$ of the initial one. The concentrated solution was subsequently placed onto a hot plate at about $75{ }^{\circ} \mathrm{C}$ to totally evaporate the solvent, producing a thermoplastic royal blue paste [27]. Further heating at about $350{ }^{\circ} \mathrm{C}$ produced the release of acetic acid-water vapours, followed by the release of brown fumes $\left(\mathrm{CO}_{2}, \mathrm{H}_{2} \mathrm{O}\right.$ and $\left.\mathrm{NO}_{\mathrm{x}}\right)$ during the slow self combustion of organic material. The remaining brownish powder was manually milled and calcined at 750 and $800{ }^{\circ} \mathrm{C}$ for $12 \mathrm{~h}$ with an intermediate manual milling to decompose the alkaline-earth carbonates. This step is very important for materials which are processed by the LFZ technique. If carbonates are present, they would decompose inside the molten zone, producing bubbles and destabilizing the crystallization front [28] leading to grain misorientations and parasitic grain growth. Moreover, some of the released $\mathrm{CO}_{2}$ could be trapped inside the solid, producing porosity, and/or decreasing the grains connectivity.

The thermally treated powders were isostatically pressed in form of cylinders (between 2 and $3 \mathrm{~mm}$ diameter) at $200 \mathrm{MPa}$. The green ceramics were used as feed in in a directional solidification process performed in a LFZ installation [29]. The textured bars were obtained using a continuous power Nd:YAG laser $(\lambda=1064 \mathrm{~nm})$, under air, at a growth rate of $30 \mathrm{~mm} / \mathrm{h}$ and $18 \mathrm{rpm}$ relative rotation between seed and feed. After the melt-grown processes, very homogeneous geometrically bars were obtained ( $2 \mathrm{~mm}$ diameter and $120 \mathrm{~mm}$ length). Bi2212 ceramic presents incongruent melting and, as a consequence, after the directional solidification process, it is necessary to perform a thermal treatment in order to form the Bi2212 superconducting phase [30]. This annealing process was performed under air, and consisted in two steps: $60 \mathrm{~h}$ at $860^{\circ} \mathrm{C}$, followed by $12 \mathrm{~h}$ at $800{ }^{\circ} \mathrm{C}$ and, finally, quenched in air to room temperature.

Structural studies of textured ceramic samples were performed by using a Rigaku D/max-B $\mathrm{X}$-ray powder diffractometer ( $\mathrm{CuK} \alpha$ radiation) with $2 \theta$ ranging between 3 and 80 degrees. 
The uncertainty of the crystal lattice parameters calculation remained in the \pm 0.00001 range. Microstructural features were determined on polished longitudinal cross-sections of samples, in a field emission scanning electron microscope (FESEM, Zeiss Merlin) equipped with an energy dispersive spectroscopy (EDX) system. The magnetic hysteresis measurements of samples were performed at temperature of $10 \mathrm{~K}$ and an applied field of $\pm 1 \mathrm{~T}$, and $\mathrm{M}(\mathrm{T})$ measurement obtained under applied fiel of 50 Oe in ZFC mode with a 7304 model Lake Shore VSM. Transport measurements were performed by conventional four-point probe configuration on about $30 \mathrm{~mm}$ long samples.

\section{Results and Discussion}

The powder XRD patterns for all samples are shown in Fig. 1. As can be seen, all peaks detected above $\% 3$ of the maximum intensity value and labeled by + are related to the major Bi-2212 phase. The unit-cell parameters and average crystal sizes calculated by using least square fitting and the Debye-Scherrer formula [31], respectively, are given in Table 1. The crystal symmetries of all samples are obtained as pseudo-tetragonal structure with $a-b \approx 5.40$ $\AA$. The $c$-parameters of all samples are found in the vicinity of $30.8 \AA$, which is in good agreement with the crystal structure of Bi-2212 phase [32]. The crystal size indicating the crystallinity first increases with increasing of $\mathrm{Na}$ concentration up to $0.10 \mathrm{Na}$ and then it starts to decrease. As a consequence, an increasing of Na-concentration may help to the growth mechanism of Bi-2212 grains in grain boundaries. On the other hand, lower melting point of system arising from more concentration of $\mathrm{Na}$ induces a small amount of liquid phase in the grain boundaries. Those liquid phases contribute to diffusion mechanism that can help to growing of the grains.

Fig. 2 shows the SEM micrographs obtained from longitudinal polished sections of samples. As it can be seen, the SEM images have different contrasts indicating the different phases in the structures. It can be also clearly seen that Bi-2212 (grey phase indicated by \#1) is the major phase observed in all samples. The phase marked as \#2 (white contrast) are identified as Bi-2201 phase. Finally, black spots marked as \#3 correspond to strontium rich phase. It is observed that all samples are formed of well-textured grain structure of typical Bi-2212 superconductor phase. In addition, the sample having $0.075 \mathrm{Na}$ contains less $\mathrm{Bi}-2201$ phase (white color) those of the others. Therefore, it may positively contribute to transport properties and superconducting transition temperature, $T_{C}$, of this sample. 
Fig. 3 shows the magnetizations as a function of temperature measured under applied magnetic field of 50 Oe, perpendicular to the growth direction of fibers. As can be seen from the inset figure, the critical onset temperatures, $T_{C}$, corresponding to diamagnetic transition are evaluated to be around $92 \mathrm{~K}$ with a sharp drop for all samples indicating a good quality, homogeneity, and texturing of the fibers. The $T_{C}$ values slowly vary depending on the Naconcentration. Initially, it increases with increasing Na-concentration up to $0.1 \mathrm{Na}$ substitution for $\mathrm{Ca}$, and then it decreases with increasing Na-concentration. The best $T_{C}$ value is obtained as $93.3 \mathrm{~K}$ for the sample having \% 7.5 of $\mathrm{Na}$, which is also very close to superconducting transition temperature value of single crystal of Bi-2212 phase [33]. This result is compatible with its SEM micrograph demonstrating less fraction of Bi-2201 phase, larger well oriented grain structure of Bi-2212.

Figure 4 illustrates the magnetic hysteresis loops measured at $10 \mathrm{~K}$, between the applied magnetic fields of $\pm 9 \mathrm{~T}$, perpendicular to the growth direction. The general behavior of hysteresis curves appeared in the figure indicates that the magnetization values are strongly dependent to Na-substitution. Furthermore, the reversible and symmetrical shapes of loops imply that pinning mechanism commonly occurs by bulk pinning rather than surface and geometrical barriers in low fields [34]. As it can be seen, the M-H loops of 10\%, 15\% and 5\% are relatively larger than those of pure sample. A large hysteresis loop and high magnetization value lead to a high intra-grain critical current density value. It is concluded that diamagnetic response may be firstly affected positively up to $10 \%$ of Na-substitution level, than it starts to be negatively affected by rising of $\mathrm{Na}$ content.

The intragranular critical current density $J_{c}$, values of the samples were calculated from the hysteresis data measured at $10 \mathrm{~K}$, using the Bean's model [35].

Jc $=30 \frac{\Delta M}{d}$

where $J_{C}$ is the critical current density in ampéres per square centimeter of a sample. $\Delta M=M_{+}-M_{-}$is measured in electromagnetic units per cubic centimeter, and $d$ is the thickness of the sample.

Figure 5 shows intragranular critical current densities for all samples, as a function of applied magnetic field, at $10 \mathrm{~K}$. 
It is observed that $J c^{\text {mag }}$ values gradually decrease with increasing magnetic field values. It can be also seen that $\mathrm{Na}$ substitution for $\mathrm{Ca}$ site of $\mathrm{Bi}-2212$ system generally contributes to the pinning mechanism. The reason may be explained by using SEM micrographs of fibers composing of well-textured grain orientations induced by Na-content. A larger and textured grain implies strong grain boundaries revealing to the high $J_{C}{ }^{\text {mag }}$ values. The sample having 10 percentage of Na-substitution exhibits the highest $J_{C}{ }^{m a g}$ value. It is found as $1.33 \times 10^{5}$ $\mathrm{A} / \mathrm{cm}^{2}$ at $10 \mathrm{~K}$ in the absence of magnetic field.

We have also measured directly the critical current values of the samples. Figure 6 shows intergrain critical current density, $J_{C}$, versus Na-substitution level at $77 \mathrm{~K}$. In this figure, it seems that the transport $J_{C}$ values of all Na-substituted samples are relatively higher than the pure sample, due to better texturing and larger grain size. The best $J_{C}$ value was obtained as $1.3 \times 10^{3} \mathrm{~A} / \mathrm{cm}^{2}$ at $77 \mathrm{~K}$ for $\mathrm{x}=0.05$. There is a local minimum for Na-substituted samples at $\mathrm{x}=0.1$, than $J_{C}$ increase gradually for more Na concentration.

\section{Conclusion}

In this study, the effect of $\mathrm{Na}$ substitution for $\mathrm{Ca}$ on the structural and superconducting properties of Bi-2212 prepared by polymer solution method and then directionally grown using the laser floating zone (LFZ) technique has been investigated. XRD measurements suggest that all fiber samples have grown with nearly single Bi-2212 phase independently from Na-substitution. The SEM micrographs and EDX results of all samples indicate that Bi2212 is major phase with a rarely appearance of Bi-2201 phase and phase rich in Sr. According to $M-T$ results, Na-substitution results an improvement in superconducting transition temperature $T_{C}$, as about $1 \mathrm{~K}$ for $\mathrm{x}=0.075$. The $M-H$ measurements indicate that the hysteresis loops relatively become larger for $\mathrm{x}=0.05,0.1$, and 0.15 with texturing process. The critical current density is improved for some Na-substitution levels, implying well textured and larger grain clusters compared with the pure fiber sample. The highest intragranular $J_{C}^{m a g}$ value was calculated as $1.33 \times 10^{5} \mathrm{~A} / \mathrm{cm}^{2}$ at $10 \mathrm{~K}$ for $\mathrm{x}=0.1$, while the highest intergranular $J_{C}$ was measured as $1.3 \times 10^{3} \mathrm{~A} / \mathrm{cm}^{2}$ at $77 \mathrm{~K}$ for $\mathrm{x}=0.05$.

\section{Acknowledgement}

This work is supported by Research Fund of Çukurova University, Adana, Turkey, under grant contracts no: FBA-2015-3934. 


\section{References}

[1] C. Michel, M. Hervieu, M.M. Borel, A. Grandin, F. Deslands, J. Provost, B. Raveav, Superconductivity in the Bi-Sr-Cu-O System, Z. Phys. B 86, 421 (1987)

[2] H. Maeda, Y. Tanaka, M. Fukutumi, T. Asano, A new high-Tc oxide superconductor without a rare-earth element, Jpn. J. Appl. Phys. 27, 209 (1988)

[3] P. Majewski, H. L. Su, M. Quilitz, Relationships between the chemical composition and properties of the high-temperature superconductor $\mathrm{Bi}_{2+x} \mathrm{Sr}_{2-y} \mathrm{Ca}_{1+y} \mathrm{Cu}_{2} \mathrm{O}_{8+d}$, J. Mater. Sci. 32, 5137 (1997)

[4] N. Türk, H. Gündogmus, M. Akyol, Z. D. Yakıncı, A. Ekicibil, B. Özçelik, Effect of Tungsten (W) Substitution on the Physical Properties of Bi-(2223) Superconductors, J Supercond Nov Magn27, 711 (2014)

[5] V. Lennikov, B. Özkurt, L. A. Angurel, A. Sotelo, B. Özçelik, G. F. de la Fuente, Microstructure and Transport Properties of Bi-2212 Prepared by CO2 Laser Line Scanning, J Supercond.Nov.Magn. 26, 947, (2013)

[6] B. Özçelik, B. Özkurt, M.E. Yakıncı, A. Sotelo, M. A. Madre, Relationship Between Annealing Time and Magnetic Properties in Bi-2212 Textured Composites,J Supercond Nov Magn. 26:873 (2013)

[7] D. Yazıcı, B. Ozçelik, M.E. Yakıncı, Improvement of High Tc Phase Formation in BPSCCO Superconductor by Adding Vanadium and Substituting Titanium,J. Low Temp. Phys. 163, 370 (2011)

[8] A. Sotelo, M. Mora, M. A. Madre, J. C. Diez, L. A. Angurel, G. F. de la Fuente, Ag distribution in thick Bi-2212 floating zone textured rods, J. Eur. Ceram. Soc. 25, 2947 (2005)

[9] A. Sotelo, P. Majewski, H. S. Park, F. Aldinger, Synthesis of highly pure Bi-2223 ceramics using defined precursors, Physica C 272, 115 (1996)

[10] M. Mora, A. Sotelo, H. Amaveda, M. A. Madre, J. C. Diez, L. A. Angurel, G. F. de la Fuente, Ag addition effect on laser textured Bi-2212 samples, Bol. Soc. Esp. Ceram. V. 44, $199(2005)$

[11] G. F. de la Fuente, A. Sotelo, Y. Huang, M. T. Ruiz, A. Badia, L. A. Angurel, F. Lera, R. Navarro, C. Rillo, R. Ibañez, D. Beltran, F. Sapiña, A. Beltran, Polymersolution processing of (Bi,Pb)-Sr-Ca-Cu-O, Physica C185, 509 (1991)

[12] S. Bal, M. Dogruer, G. Yıldırım, A. Varilci, C. Terzioglu, Y. Zalaoglu, Role of Cerium Addition on Structural and Superconducting Properties of Bi-2212 System, J. Supercond. Nov. Magn. 25, 847 (2012) 
[13] B.Ozkurt, Enhancement in superconducting transition temperature and Jc values in Nadoped $\mathrm{Bi}_{2} \mathrm{Sr}_{2} \mathrm{Ca}_{1} \mathrm{Cu}_{2-\mathrm{x}} \mathrm{Na}_{\mathrm{x}} \mathrm{O}_{\mathrm{y}}$ superconductors, J Mater Sci: Mater Electron., 24, 2426 (2013)

[14] B. Özçelik, M.Gürsul, A. Sotelo, M. A. Madre, Effect of K substitution on Structural, Electrical and Magnetic Properties of Bi-2212 system, J. Mater. Sci.: Mater. Electron. 25, 4476 (2014)

[15] B. Özçelik, M.Gürsul, A. Sotelo, M. A. Madre, Improvement of superconducting properties in Na-doped BSCCO superconductor, J. Mater. Sci.: Mater. Electron. 26, 441 (2015)

[16] B. Özçelik, M.Gürsul, A. Sotelo, M. A. Madre, Improvement of the intergranular pinning energy in the Na-doped Bi-2212 superconductors, J. Mater. Sci.: Mater. Electron. $26,2830(2015)$

[17] B. Özçelik, E.Yalaz, M.E.Yakıncı, A. Sotelo, M. A. Madre, The Effect of K Substitution on Magnetoresistivity and Activation Energy of Bi-2212 System, J. Mater. Sci.: Mater. Electron. 28, 553 (2015)

[18] B. Özkurt, M. A. Madre, A. Sotelo, M.E. Yakıncı, B. Özçelik, Relationship Between Growth Speed, Microstructure, Mechanical and Electrical Properties in Bi2212/Ag Textured Composites, J. Supercond. Nov. Magn. 25, 799 (2012)

[19] H.Gündoğmuş, B. Özçelik, A. Sotelo, M. A. Madre, Effect of Yb-substitution on thermally activated flux creep in the $\mathrm{Bi} 2 \mathrm{Sr} 2 \mathrm{CaCu} 2-\mathrm{xYbxOy}$ superconductors, J Mater Sci: Mater Electron 24, 2568 (2013)

[20] A. Özaslan, B. Özçelik, B. Özkurt, A. Sotelo,M.A. Madre, Structural, Electrical, and Magnetic Properties of the Co-Substituted Bi-2212 System Textured by Laser Floating Zone Technique, J Supercond Nov Magn 27, 53 (2014)

[21] B. Özçelik, C. Kaya, H. Gündoğmuş, A. Sotelo, M.A. Madre, Effect of Ce Substitution on the Magnetoresistivity and Flux Pinning Energy of the Bi2Sr2Ca1-xCexCu2O8+d Superconductors, J Low Temp Phys. 174, 136 (2014)

[22] A. Sotelo, M. Mora, H. Amaveda, J. C. Diez, L. A. Angurel, M. C. Mayoral, Study of the variation of the E-I curves in the superconducting to normal transition of Bi-2212 textured ceramics by Pb addition, Bol. Soc. Esp. Ceram. V. 45, 228 (2006) 
[23] G. F. de la Fuente, M.T. Ruiz, A. Sotelo, A. Larrea, R. Navarro, Microstructure of laser floating zone (LFZ) textured ( $\mathrm{Bi}, \mathrm{Pb})-\mathrm{Sr}-\mathrm{Ca}-\mathrm{Cu}-\mathrm{O}$ superconductor composites, Mater. Sci. Eng. A 173, 201 (1993)

[24] M.Gürsul, A. Ekicibil, B. Özçelik, M. A. Madre, A. Sotelo, Sintering Effects in NaSubstituted Bi-(2212) Superconductor Prepared by a Polymer Method, J Supercond Nov Magn 28, 1913 (2015)

[25] B. Özçelik, M.Gürsul, A. Sotelo, M. A. Madre, Improvement of the intergranular pinning energy in the Na-doped Bi-2212 superconductors, J. Mater. Sci.: Mater. Electron. 26, $2830(2015)$

[26] H. Gundogmus, B. Ozcelik, B. Ozkurt, A. Sotelo, M.A. Madre, Physical, mechanical and magnetic properties of the $\mathrm{Yb}$ substituted $\mathrm{Bi} 2 \mathrm{Sr} 2 \mathrm{Ca} 1 \mathrm{Cu} 2 \mathrm{Oy}$ textured superconductor J. Supercond. Nov. Magn. 26, 111 (2013)

[27] A. Sotelo, G. F. de la Fuente, F. Lera, D. Beltran, F. Sapiña, R. Ibañez, A. Beltran, M. R. Bermejo, Novel polymer solution synthesis of the $110 \mathrm{~K}$ superconducting phase in the bismuth system, Chem. Mater. 5, 851-856 (1993)

[28] A. Sotelo, Sh. Rasekh, M. A. Madre, J. C. Diez, Precursor Influence on the Electrical Properties of Textured Bi-2212 Superconductors, J. Supercond. Nov. Magn. 24, 19 (2011)

[29] M. F. Carrasco, F. M. Costa, R. F. Silva, F. Gimeno, A. Sotelo, M. Mora, J. C. Diez, L. A. Angurel, Textured BI-Sr-Ca-Cu-O rods processed by laser floating zone from solid state or melted precursors, Physica C 415, 163 (2004)

[30] M. Mora, A. Sotelo, H. Amaveda, M. A. Madre, J. C. Diez, F. Capel, J. M. LopezCepero, Properties variation of Bi-2212 directionally solidified induced by $0.4 \mathrm{~Pb}$ substitution, J. Eur. Ceram. Soc. 27, 3959 (2007)

[31] P. Scherrer, Bestimmung der Größe und der inneren Struktur von Kolloidteilchen mittels Röntgenstrahlen, Göttinger Nachrichten Gesell 2 (1918)

[32] X. Zhao, W. Wu, X. Sun, X.G. Li, New experimental evidence of the structural modification in single crystal $\mathrm{Bi} \mathrm{Sr} \mathrm{CaCu} \mathrm{O}$ by X-ray diffraction observation, Physica $\mathrm{C}$ 320,225 (1999)

[33] Eisaki H, Kaneko N, Feng D L, Damascelli A, Mang P K, Shen K M, Shen Z X and Greven M, Effect of chemical inhomogeneity in bismuth-based copper oxide superconductors, Phys. Rev. B 69, 064512 (2004) 
[34] B. Özkurt, A. Ekicibil, M. Ali Aksan, B. Özçelik, M. E. Yakıncı,K. Kiymaç, Structural and Physical Properties of $\mathrm{Nd}$ Substituted Bismuth Cuprates $\mathrm{Bi}_{1.7} \mathrm{~Pb}_{0.3-}$ ${ }_{x} \mathrm{Nd}_{\mathrm{x}} \mathrm{Sr}_{2} \mathrm{Ca}_{3} \mathrm{Cu}_{4} \mathrm{O}_{12+\mathrm{y}}$, J. Low Temp Phys, 149, 105 (2007)

[35] C.P. Bean, Magnetization of Hard Superconductors, Phys. Rev. Lett. 8, 250 (1962)

\section{Figure Captions}

Figure-1. XRD patterns of the samples which are milled. Peaks are indicated by + corresponding to the Bi-2212.

Figure-2. SEM micrographs performed on longitudinal polished sections of the samples.

Figure-3. Magnetic moment as a function of temperature for different Na-concentrations.

Figure-4. Magnetic Hysteresis curves obtained for the all samples at $10 \mathrm{~K}$.

Figure-5. Calculated critical current densities, $J c$, of the samples, as a function of applied field at $10 \mathrm{~K}$.

Figure-6. Critical current density $J c$, at 77K, vs. Na concentration for Bi-2212 Fibers.

\section{Table}

Table-1. $T_{C}$ values determined from M-T measurement, unit-cell parameters, crystal size, and $\mathrm{J}_{\mathrm{C}}$ values for all concentration. 


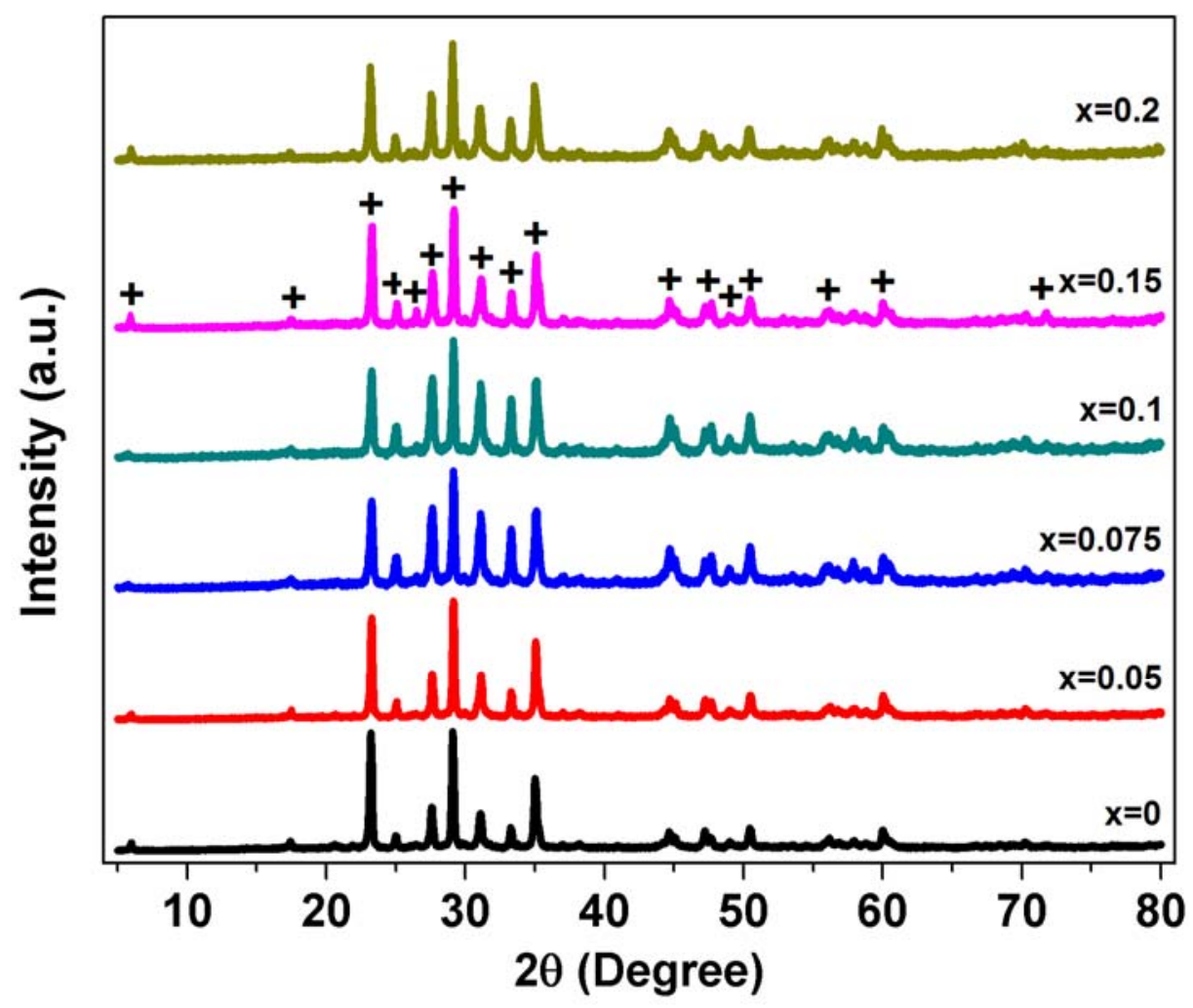

Fig.1. 


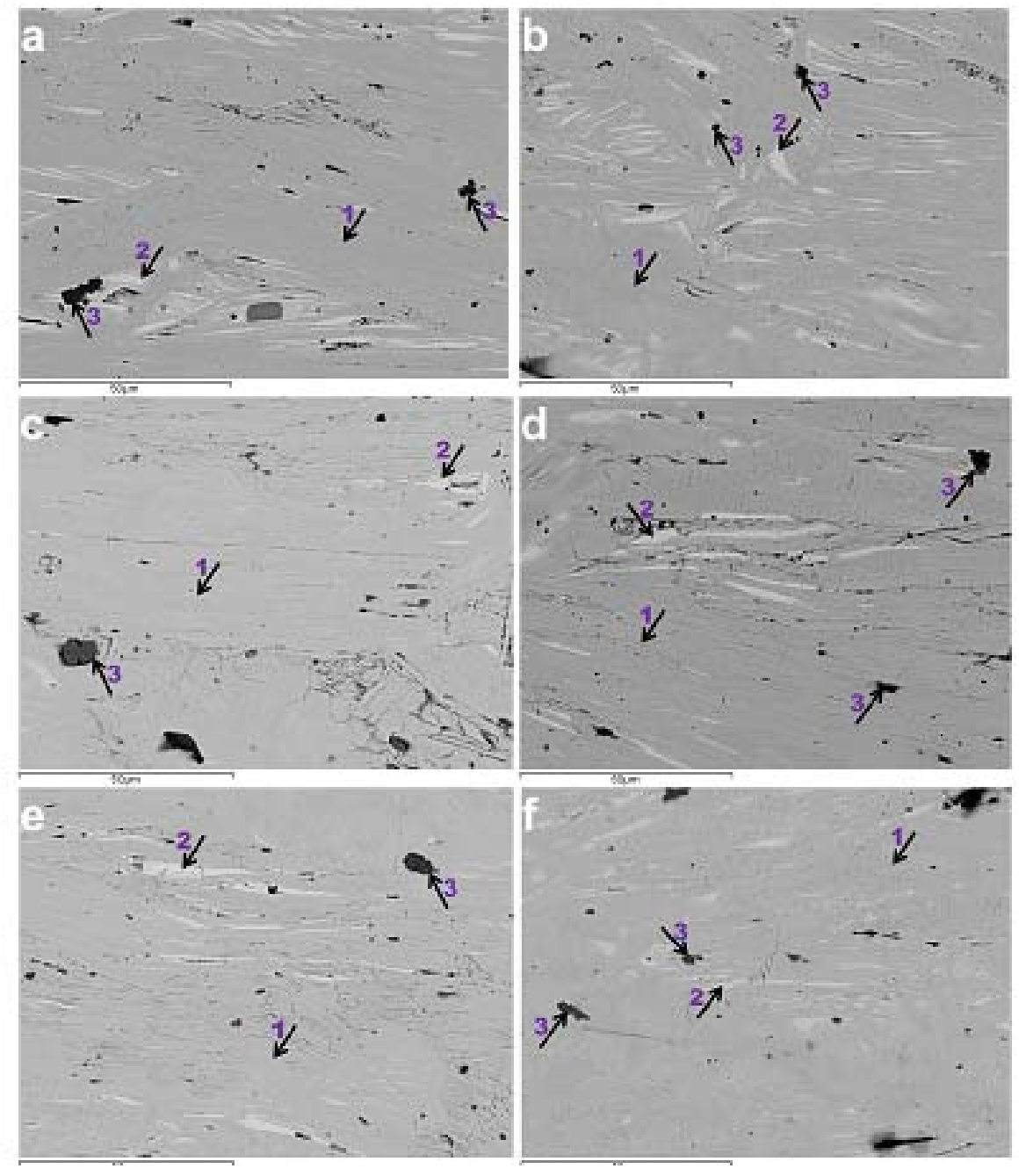

Fig.2. 


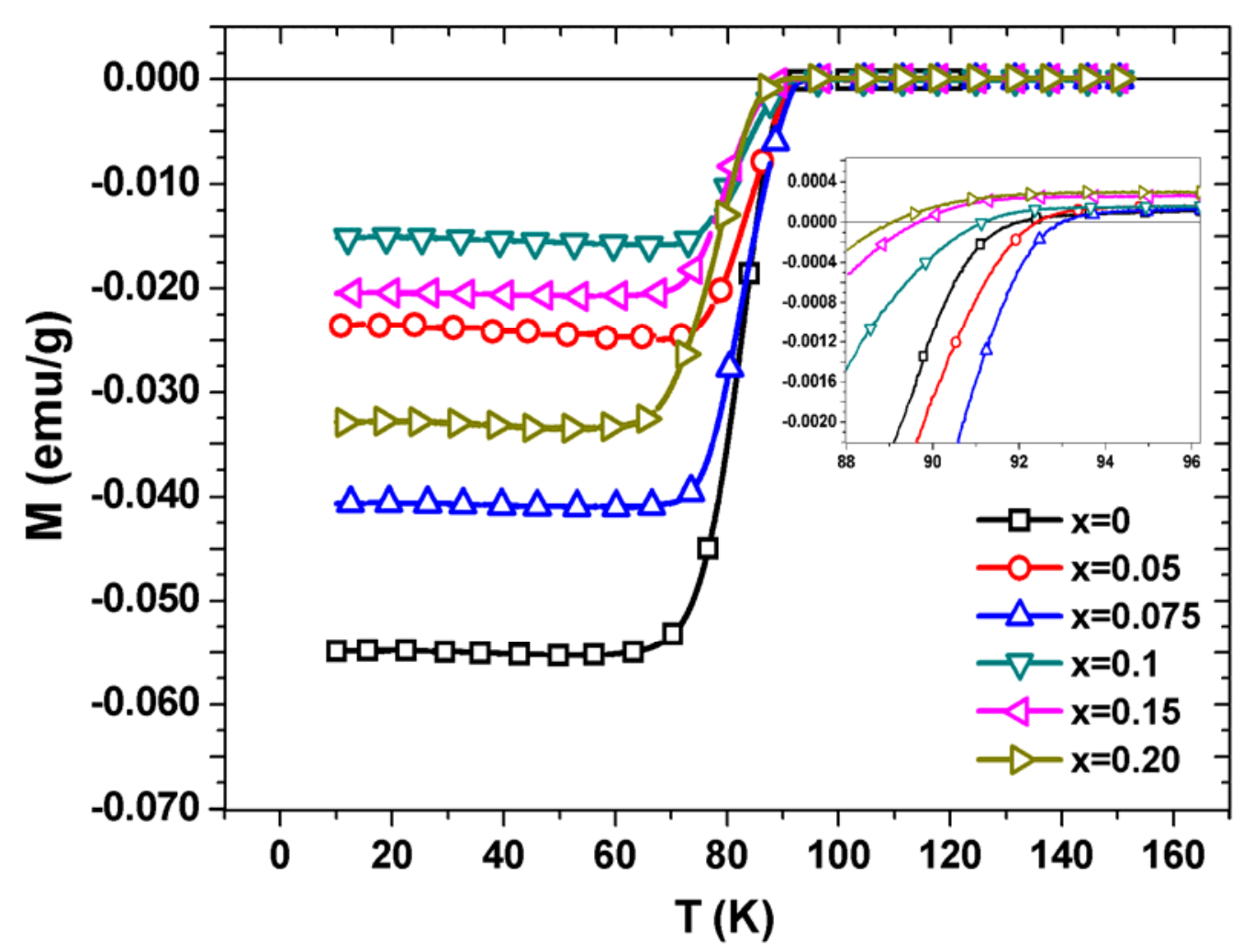

Fig.3. 


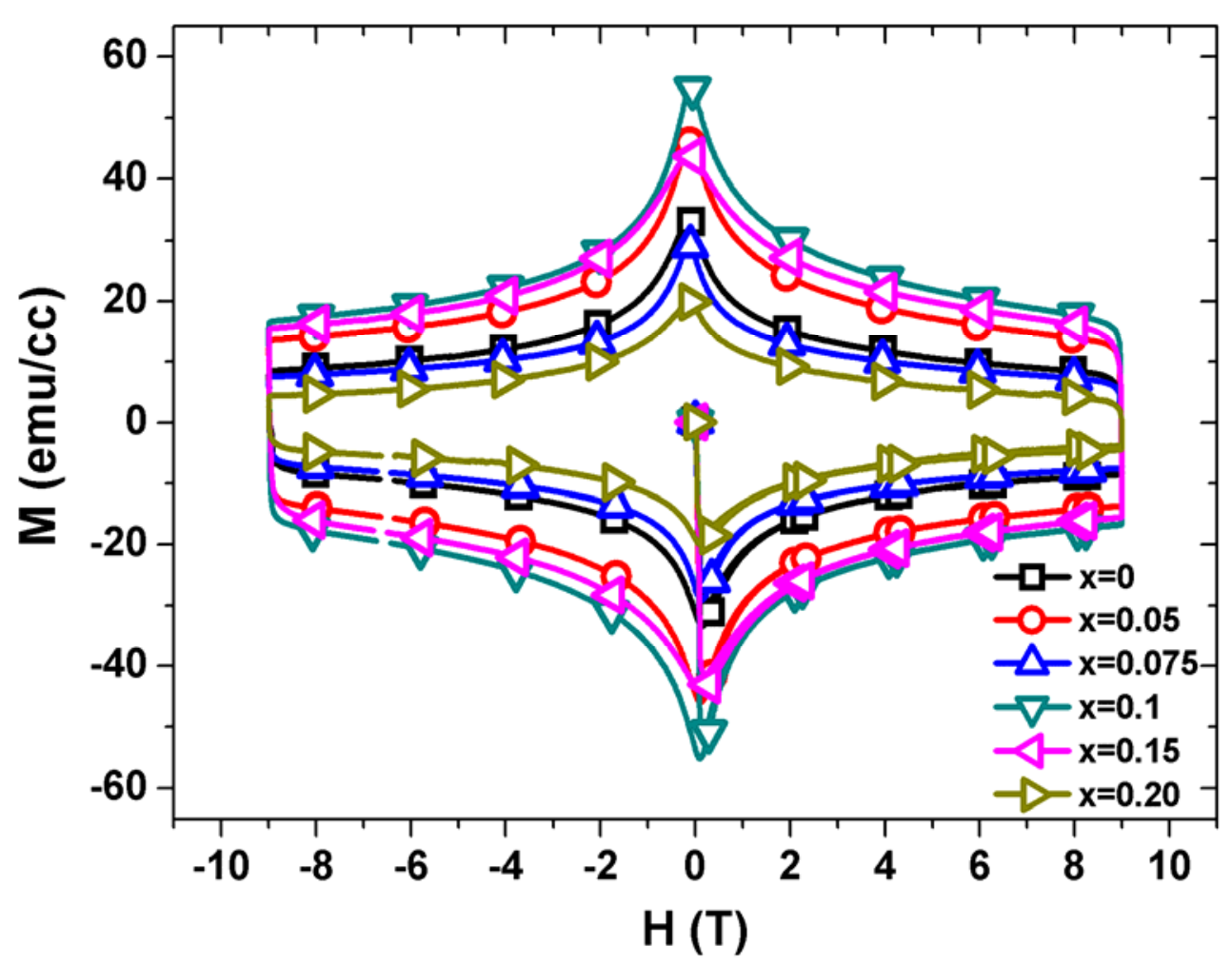

Fig.4. 


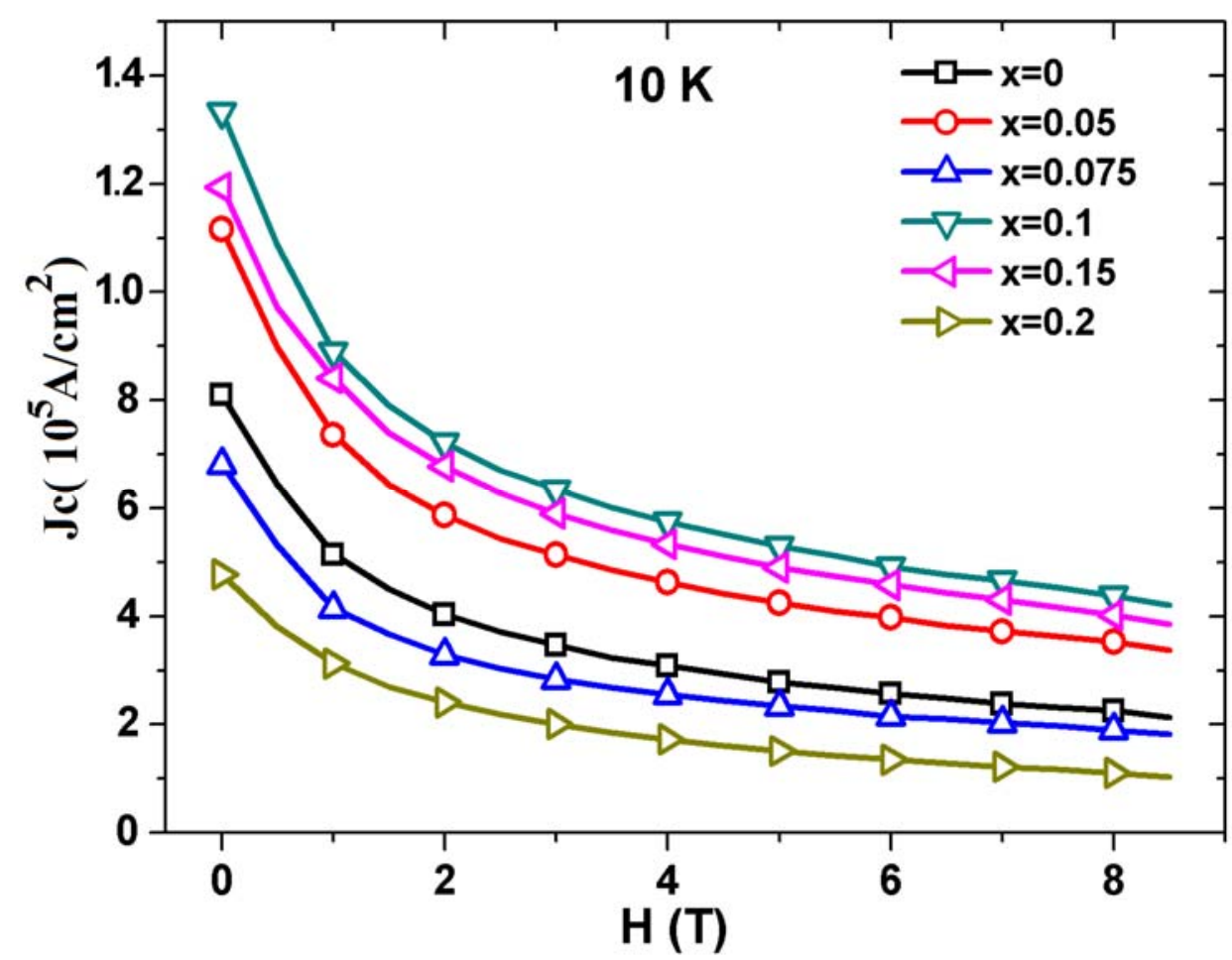

Fig.5. 


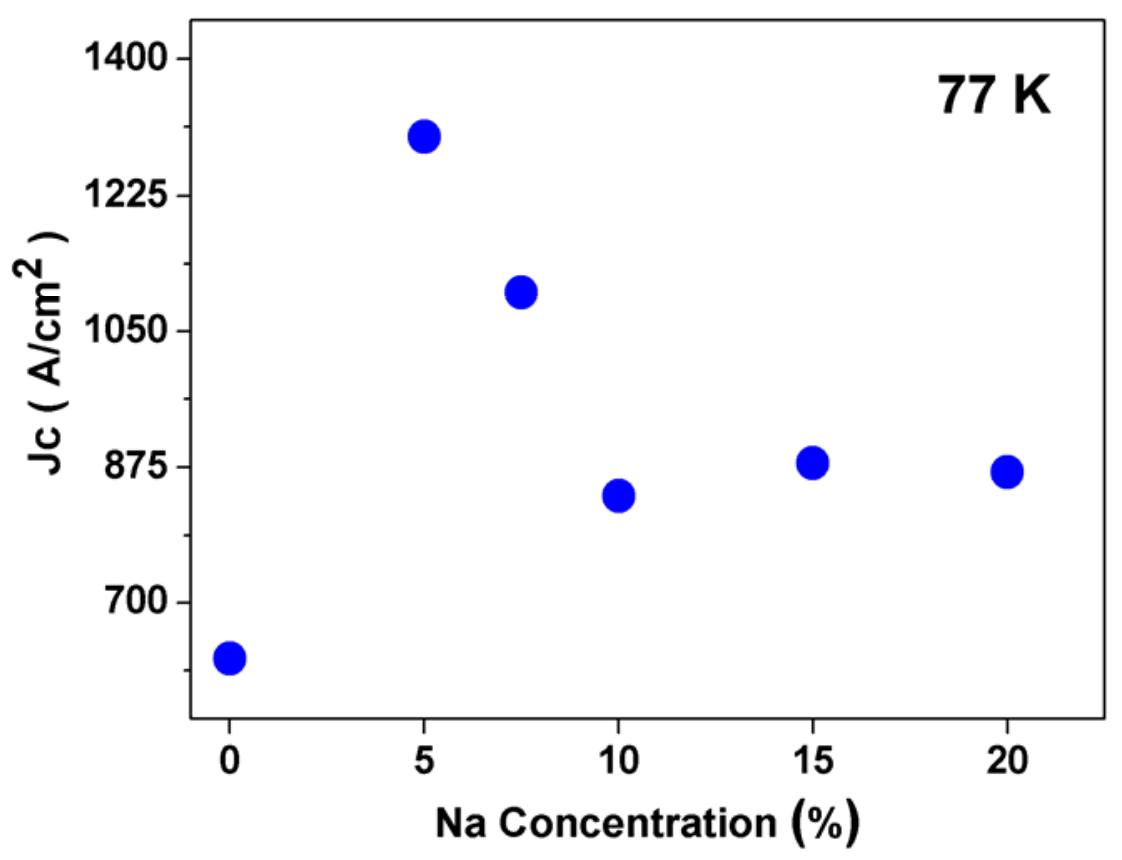

Fig.6. 


\begin{tabular}{|l|l|l|l|l|l|c|}
\hline Na-Content & $\boldsymbol{T}_{\boldsymbol{C}}(\mathbf{K})$ & $\begin{array}{l}\text { Unit-cell } \\
\text { Parameter } \\
\boldsymbol{a} \approx \boldsymbol{b}(\dot{\mathrm{A}})\end{array}$ & $\begin{array}{l}\text { Unit-cell } \\
\text { Parameter } \\
\boldsymbol{c}\end{array}$ & $\begin{array}{l}\text { Crystal } \\
\text { Size } \mathbf{L} \\
(\dot{A})\end{array}$ & $\begin{array}{l}\text { Intragranular } \\
\mathbf{J}_{\mathbf{C}}\left(\mathbf{A} / \mathbf{c m}^{2}\right) \\
\text { at } \mathbf{1 0} \mathbf{~ K}\end{array}$ & $\begin{array}{l}\text { Intergranular } \\
\mathbf{J}_{\mathbf{C}}\left(\mathbf{A} / \mathbf{c m}^{2}\right) \\
\mathbf{a t} \mathbf{7 7} \mathbf{~ K}\end{array}$ \\
\hline $\mathrm{x}=0$ & 92.5 & 5.4212 & 30.8945 & 430.12 & $0.81 \times 10^{5}$ & $0.63 \times 10^{3}$ \\
\hline $\mathrm{x}=0.05$ & 92.6 & 5.4457 & 30.9106 & 442.88 & $1.11 \times 10^{5}$ & $1.30 \times 10^{3}$ \\
\hline $\mathrm{x}=0.075$ & 93.3 & 5.4305 & 30.8382 & 444.86 & $0.68 \times 10^{5}$ & $1.10 \times 10^{3}$ \\
\hline $\mathrm{x}=0.1$ & 91.4 & 5.4289 & 30.9439 & 488.47 & $1.33 \times 10^{5}$ & $0.84 \times 10^{3}$ \\
\hline $\mathrm{x}=0.15$ & 89.9 & 5.4211 & 30.8998 & 416.94 & $1.19 \times 10^{5}$ & $0.88 \times 10^{3}$ \\
\hline $\mathrm{x}=0.2$ & 89.3 & 5.4243 & 30.9107 & 410.07 & $0.47 \times 10^{5}$ & $0.87 \times 10^{3}$ \\
\hline
\end{tabular}

Table-1. 